\title{
Capítulo V \\ La centralidad del lenguaje como auténtica vocación de las humanidades
}

"-Tan solo por la educación puede el hombre llegar a ser hombre. El hombre no es más que lo que la educación hace de él"

(Immanuel Kant)

La propuesta de $\mathrm{H}$. Arendt que se acaba apenas de esbozar en sus líneas esenciales, enfatiza ante todo en la recuperación de la vita activa o de la dimensión propiamente política de la actividad en las democracias. Ello supone la desmedida preponderancia que se le dio en la antigüedad y en el medioevo a la vita contemplativa y, de otro lado, una crítica al activismo mercantilista y utilitarista que prevalece en el mundo moderno. Asintiendo el acierto de estos análisis y su legítima raigambre humanista, otros autores como H-G. Gadamer si bien sintonizan con estos análisis y propuestas, se preguntan si el problema, al menos en el ámbito educativo y cultural, no se relaciona más directamente con un modelo de ciencia, de conocimiento y, en últimas, de humanidad que únicamente con la preponderancia de unos estilos de vida sobre otros o con un modelo de desarrollo económico (1977; 1992; 2001).

Gadamer ha llamado la atención sobre lo que él considera la auténtica vocación de las humanidades, en particular frente a las exigencias y pretensiones de una ciencia inspirada en un modelo físico-matemático. En sus obras otorga un énfasis a la centralidad del lenguaje en todas las acciones relativas al entendimiento, a la acción humana y al consenso social: "el lenguaje es el medio en el que se realiza el acuerdo de los interlocutores y el consenso sobre la cosa” (1977, p. 462). Los saberes científicos, técnicos y tecnológicos han fijado el modelo de las «soluciones técnicas» como paradigma, por excelencia, del conocimiento y del saber, para la época actual. La «ciencia» en el lapso de un siglo 
y medio se ha rodeado de una aureola de prestigio que ha puesto en duda el valor de otros tipos de saber, algunos incluso más antiguos que ella (Mardones, 2007). La pretendida infalibilidad de las 'soluciones científicas' ha cautivado no solo la imaginación popular, sino que ha permeado otros tipos de saberes no científicos -como las letras, las humanidades y las ciencias humanas- hasta el punto de condicionar la manera como estos saberes se comprenden a sí mismos (cf. Goldmann, 1979).

Estos saberes, a pesar de que tienen sus propios modos y modelos de conocimiento, con frecuencia se acomodan a las exigencias del método científico y se suman al coro de las soluciones técnicas. Incluso la teología, a pesar de poseer una tradición milenaria, se ha visto tentada a acomodarse a ese nuevo paradigma (Peukert, 2000; Pannenberg, 1981; Milbank, 2004). La dificultad con este tipo de soluciones radica en que, muy a menudo, implican dejar de lado o ignorar la "cuestión humana», es decir, la irreductibilidad de la pluralidad fundamentada en la libertad y en la dignidad. Como lo señala Starck, respecto a una visión demasiado determinista de la conducta humana como la de B. F. Skinner (Cf. Skinner, 1987; Starck, 2008, p. 246), el énfasis en el control en la 'técnica conductual', le resta espacio a la libertad y a su contrapartida que es la dignidad:

Bajo el título de 'más allá de la libertad y la dignidad' Skinner pone en duda los controles que ejerce el hombre «autónomo» y pone a prueba los controles que ejerce el medio social. Este autor pone su esperanza en una "técnica de la conducta» que hace innecesarios los conceptos de libertad y dignidad (...) La realización de la tesis de Skinner sería, por eso (contenido cerrado), igual de legitima que el egoísmo radical. Además, tal planteamiento supone una ayuda interpretativa para la comprensión de la garantía de la dignidad jurídico-constitucional, pues ésta tiene que ser determinada para lograr su protección y respeto, si es que no se quiere que tenga un contenido vacío, o sirva como cómoda coartada para políticas ya delineadas sobre el hombre (2010, p. 246-7).

Esta reivindicación del cultivo de lo humano a través de las artes, del diálogo y del ejercicio de la libertad de expresión, hace que la propuesta de Gadamer, a la vez, que recupera la tradición clásica y renacentista, se coloque como punto de referencia contemporáneo ante una sociedad fascinada con la cultura de masas. Como señala Grondin, al estudiar el 
pensamiento educativo de Gadamer, en la comprensión de las singularidades de la existencia humana lo decisivo del conocimiento radica en cultivar la verdad que se alcanza en el diálogo y en no escindir la teoría de la praxis ni la acción del discurso (2012, p. 5).

\section{La reivindicación de las humanidades.}

Para H-G. Gadamer, el ámbito de la presentación o, más bien, de la reivindicación de las humanidades como una forma legítima de conocimiento de lo humano se ubica en la discusión entre ciencias naturales y ciencias del espíritu que se ha prolongado desde mediados del siglo XIX hasta nuestros días: "el ser del espíritu está esencialmente unido a la idea de formación” (1977, p. 41). Como bien lo ha caracterizado Mardones, esta discusión constituye el trasfondo de las reivindicaciones, pues "no hay consenso en las llamadas ciencias del espíritu, culturales, humanas o sociales acerca de la fundamentación de su quehacer" (2007, p.19). En Gadamer, la obsesiva búsqueda de conformidad de la moral, de la ética, de la política y de la filosofía con respecto al exitoso modelo de las ciencias naturales ha llevado a una enajenación en todos los saberes que dependen más de los razonamientos dialécticos que de las certezas matemáticas. De este intento de asimilación al modelo científico han sido precursores D. Hume, J. Stuart Mill y A. Comte entre otros. Pero, si bien algunas de las Ciencias Humanas como la psicología conductual y la neuropsicología ya han producido avances en este sentido, la realidad general de otros saberes y disciplinas que se ocupan de la existencia social y de la actividad política, no está en camino hacia esta búsqueda de conformidad. Por lo que habría que reconocer que "el verdadero problema que plantean las ciencias del espíritu al pensamiento es que su esencia no queda correctamente aprehendida si se las mide según el patrón del conocimiento progresivo de las leyes" (Gadamer, 1977, p. $32)$.

A su modo de ver, a esta influencia tan fuerte del modelo de las ciencias formales y naturales no se han sustraído diversos intentos de fundamentación de las ciencias del espíritu desde el reconocimiento de otras lógicas del naturalista $\mathrm{H}$. Helmoltz, pasando por la fundamentación histórica de J. G. Droyssen, hasta la fundamentación psicológica de W. Dilthey (1977, p. 33-37). Por ello, Gadamer retorna a algunos 
conceptos claves del humanismo con los que muestra que las potencialidades del ser humano no están limitadas a las configuraciones culturales, sino que son susceptibles de una apertura a las novedades que pueden provenir del cultivo de su propia humanidad y a la transformación histórica de la humanidad. De esta manera, se muestra que el saber no se desliga del ser.

Para Gadamer, en las humanidades el concepto de "formación» constituye el elemento clave que permite fundamentar ese ámbito del saber. Este concepto diferenciaría lo propio de las humanidades frente a las ciencias, a las matemáticas u otros tipos de conocimiento de carácter analítico o demostrativo:

Lo que convierte en ciencias a las del espíritu se comprende mejor desde la tradición del concepto de formación que desde la idea del método de la ciencia moderna. En este punto nos vemos remitidos a la tradición humanista, que adquiere un nuevo significado en su calidad de resistencia ante las pretensiones de la ciencia moderna (1977, p. 47).

A este concepto clave, Gadamer les suma otros tres que, a su parecer, constituyen los conceptos básicos del humanismo: sensus communis, capacidad de juicio y gusto. Estos conceptos encuadran una propuesta humanista que constituye el fundamento o base de todas las reflexiones y actividades tendientes a la organización de la vida social, en particular, la educación. En lo esencial, estos cuatro conceptos y otros vinculados a la tradición humanista que se presentarán más adelante, tienen una relación directa con la pedagogía, ya que se fundan en el ideal de "formación» (Al. Bildung). Este ideal de «formación», es entendido, en general, como "el modo específicamente humano de dar forma a las disposiciones y capacidades naturales del ser humano" (Gadamer, 1977, p. 39). Esta manera de entender la formación tiene ciertas resonancias de la cultura o cultivo de las propias capacidades como acto de la libertad personal y obligación consigo mismo, del desarrollo armónico de la sensibilidad y el carácter y de la tradición mística del ser humano formado a imagen de la divinidad. En lo específico, la formación o Bildung "está estrechamente vinculada a las ideas de enseñanza, aprendizaje y competencia personal” (Gadamer, 1977, p. 38n11). En consecuencia, este ideal destaca tanto los aspectos culturales externos como los vocacionales y personalizados en cualquier proyecto forma- 
tivo. Como lo reconoce Mazeaud para la educación superior: "la enseńanza superior -frente a la cual se distingue precisamente de la enseñanza secundaria- tiene menos la función de enseñar que la de formar. Formar al estudiante es prepararlo para la vida que él escogió". (Mazeaud, 2012, págs. 12-13)

Gadamer destaca que el concepto «formación», por una parte, trasciende el mero cultivo de las capacidades previas y, por otra, se refiere más a un proceso que a un resultado. En consecuencia, es más importante el desarrollo, la progresión y la apropiación que los 'objetivos formativos' externos al proceso mismo. Siguiendo a Hegel, la racionalidad y la espiritualidad humana impulsan al ser humano a una ruptura con lo inmediato e instintivo y lo elevan hacia una capacidad de resolver lo particular desde lo general: "la esencia general de la formación humana es convertirse en un ser espiritual general" (1977, p. 41). En esto coincide con la tradición del "conócete a ti mismo" que desarrolla Nussbaum para la educación socrática deliberativa (2005) y, en general, con la tradición humanista que reconoce el poder de la capacidad racional para trascender: "el ser humano solo puede ir hacia adelante desarrollando su razón, encontrando una nueva armonía humana en reemplazo de la pre-humana que está irremediablemente perdida" (Fromm, 1988, p. 18).

Este ascenso hacia la generalidad constituye para Gadamer una auténtica tarea, labor o trabajo que le permite a la conciencia distanciarse de lo inmediato, reencontrarse a sí misma y trascender: "en cuanto que el ser humano adquiere un "poder», una habilidad, gana con ello un sentido de sí mismo” (1977, p. 41). Aparece aquí el lado práctico de la formación humana que se hace efectiva en un trabajo no alienante:

El sentimiento de sí ganado por la conciencia que trabaja contiene todos los momentos de lo que constituye la formación práctica: distanciamiento respecto a lo inmediato del deseo, de la necesidad personal y del interés privado, y atribución a una generalidad (Gadamer, 1977, p. 42).

De manera similar ocurre con el ejercicio de una profesión que exige mesura en la satisfacción de las necesidades y en el uso de las propias fuerzas, sin exceder lo saludable; la profesión no se limita a la ejecución de unas tareas determinadas o impuestas, sino que permite una apropia- 
ción de lo que es extraño, pero necesario para su ejercicio y, de manera simultánea, exige su desarrollo en diversa direcciones: "la formación comprende un sentido general de la mesura y de la distancia respecto a sí mismo, y en esa misma medida un elevarse por encima de sí mismo hacia la generalidad" (Gadamer, 1977, p. 46).

En este ascenso hacia la generalidad se exige una formación teórica a la par de una formación práctica que "lleve más allá de lo que el ser humano sabe y experimenta directamente" (Gadamer, 1977, p. 42). Y este ir más allá no es una enajenación "sino retorno a sí mismo desde el ser otro", por lo que "no es la enajenación como tal, sino el retorno a sí, que implica por supuesto enajenación, lo que constituye la esencia de la formación" (Gadamer, 1977, p. 43). La continua ruptura que el ser humano hace con su entorno inmediato, con 'su mundo', le permite tomar distancia de sí mismo y, a la vez, reinsertarse en él por la apropiación de la cultura de su pueblo: "el individuo se encuentra constantemente en el camino de la formación y de la superación de su naturalidad, ya que el mundo en el que va entrando está conformado humanamente en lenguaje y costumbres" (Gadamer, 1977, p. 43). Esta inserción en el mundo exige reconocer que "los puntos de vista generales hacia los cuales se mantiene abierta la persona formada no representan un baremo fijo que tenga validez, sino que le son actuales como posibles puntos de vista de otros" (Gadamer, 1977, pp. 46-47).

La «formación» señala para Gadamer no solo el 'proceso', sino también el 'ámbito' dentro del que se mueve quien pasa por este proceso. Este ámbito requiere del cultivo de la memoria, del olvido y del «tacto». La memoria asumida como un elemento constitutivo del ser humano y el olvido, como posibilidad de renovar la percepción que el espíritu tiene de la realidad; el tacto entendido como "una determinada sensibilidad y capacidad de percepción de situaciones, así como para el comportamiento dentro de ellas cuando no poseemos respecto a ellas ningún saber derivado de principios generales" (1977, p. 45). En esto coincidiría con Nussbaum que atribuye al autoexamen el poder de fortalecer el respeto hacia los otros y hacia sí mismo (2010, p. 81). Además de este sentido ético, se reconoce que el tacto es "una manera de conocer y una manera de ser" (Gadamer, 1977, p. 46) y, por lo mismo, se convierte en una consciencia formada que, por una parte, requiere de un cultivo o 
formación y que, por otra, actúa análogamente con la inmediatez de los sentidos: "la conciencia opera en todas las direcciones y es así un sentido general' (Gadamer, 1977, p. 47).

De esta manera, se configura la tradición humanista, inspirada en el concepto de "formación», como una alternativa contra la ciencia moderna y sus pretensiones de legitimarse a partir de un método cada vez más exacto e incluso infalible. El diálogo con los saberes antiguos motiva a una mayor valoración de la retórica como representante de una forma de conocimiento que no se limita al reconocimiento de patrones en la realidad natural, sino que se preocupa de la interacción humana y del reconocimiento del poder de la palabra como un poder 'humano'. El reconocimiento de una fuente propia de la verdad en el concepto humanista de formación lleva a relativizar las pretensiones de reducir todos los razonamientos a la lógica y todas las creencias a las evidencias histórico-críticas deducibles de sus fuentes.

\section{El retorno a la tradición humanista}

El retorno a la tradición humanista igualmente lleva a la recupera-

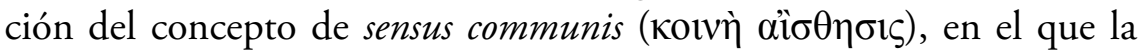
elocuencia (eloquentia) y la prudencia (prudentia) se preocupan no solo del discurso ornado, del habla eficaz, sino que recupera el arte de decir lo correcto y verdadero y que supone, en el fondo, todo el bagaje de una formación según lo anteriormente expuesto. Este ideal que combina el saber teórico de la sophía (бọía) y el saber práctico de la phrónēsis ( $\varphi \rho o ́ v \eta \sigma ı)$ ) es una forma de conocimiento ético, es decir atento a los valores universales, tal como se presentan en cada época y cultura.

Gadamer, siguiendo a Vico, se propone recuperar el valor cognitivo que las humanidades han cultivado en el "hablar bien» a partir del sensus communis y del ideal de la eloquentia, es decir, la comunicación de lo correcto y de la manera adecuada: hablar bien "significa también decir lo correcto, esto es, lo verdadero, y no solo el arte de hablar o de decir algo bien" (1977, p. 49). El sentido común es comprendido a la vez como una capacidad general de todo ser humano y como "el sentido que funda la comunidad" (Gadamer, 1977, p. 50). Con ello, se reconoce que se debe formar esta capacidad y este sentido, ya que la 
voluntad humana se orienta por la "generalidad concreta" de un colectivo humano. Este sentido común se vale de lo que el común de la gente, el lego, tiene por cierto, es decir de lo verosímil. El punto de partida de la elocuencia es precisamente este modo de conocer a partir de lo evidente y no a partir de lo causal o de lo erudito. Este saber práctico es la prudencia (Lat. prudentia; Gr. $\varphi \rho o ́ v \eta \sigma i \varsigma)$ que se ocupa del dominio ético de la realización de lo correcto en las particularidades de cada circunstancia de acuerdo con los objetivos propuestos.

Desde este punto de vista, la educación se ocuparía de la formación del sensus comunis. Este apela no solo a lo cierto (ciencia) o a lo manifiestamente reconocido (dogmática), sino que también recurre a lo verosímil. El sentido común designaría, entonces, una capacidad general del ser humano que funda la comunidad y que orienta la voluntad humana a partir de las representaciones comunes: "la formación de tal sentido común sería de importancia decisiva para la vida” (Gadamer, 1977, p. 50). La phrónèsis o prudencia, como saber práctico, está atenta al contexto de la acción, su situación y circunstancia, igualmente requiere de la capacidad de juicio para subsumir lo particular a lo general y, además, evalúa todo de acuerdo con el objetivo o propósito perseguido.

La prudencia requiere el dominio de la elocuencia que se ocupa por medio de la tópica de encontrar las imágenes sugestivas para educar la imaginación y la memoria: la tópica "sería el arte de encontrar argumentos y contribuiría a la formación de un sentido para lo convincente que trabaja instintivamente y ex tempore" (Gadamer, 1977, p. 51). Y en este campo reviste particular importancia el estudio de la historia que tiene en cuenta situaciones y circunstancias y que puede ser empleada tanto para promover una forma de conocimiento contextual y no causal como el de la ciencia e, igualmente, como para constituirse en una fuente excepcional de ejemplos aptos para la reflexión: "la conclusión desde lo general y la demostración por causas no pueden bastar porque [en el sensus communis] lo decisivo son las circunstancias" (Gadamer 1977, p. 52). En esto se acercaría a la habilidad de la imaginación narrativa de la que habla Nussbaum, característica de una formación humanista $(2005 ; 2010)$. De hecho, la narrativa histórica pone de relieve las palabras y las obras de los individuos, momentos y grupos singulares y con ello evidencia que los principios generales de 
la razón son, por sí mismos, ineficaces para regir las pasiones humanas que constituyen el núcleo real de las decisiones: "las pasiones humanas no pueden regirse por las prescripciones generales de la razón. Para ello hacen falta ejemplos convincentes" (Gadamer 1977, p. 53; cf. Cicerón, De Oratore II, 9. 36).

Esta caracterización del sentido común destaca su significado humanista, ciudadano y de razonamiento práctico (tacto e intuición). El sentido común no sería, sin más, solo el conjunto de percepciones compartidas de manera inconsciente por un colectivo, ya que si bien es un conocimiento compartido, se refiere, en primer lugar, a un reconocimiento de sentido (sentidos y sentimientos) que modula en el individuo una reflexión sobre el sentido de los discursos y acciones en función del bien común. El sentido común proporciona arraigo a las iniciativas ciudadanas que, en función de las preocupaciones particulares, dota a estas de una finalidad específica. Además, destaca el conocimiento práctico como una realidad previa y no como mero apéndice o aplicación de una teoría. Sin embargo, las evidentes ventajas que para una formación humanista tiene la consideración del sentido común y la posibilidad de verbalización mediante la retórica, carecerían del empuje y del sentido crítico si no se conjugaran con la capacidad de juicio.

La "capacidad de juicio» (Urteilskraft) actualiza de manera consciente las valoraciones que en el sentido común aparecen simplemente como criterios establecidos. En cuanto capacidad, requiere, la correcta subsunción y aplicación de lo que se ha aprendido y de lo que se sabe, consiste "en subsumir algo particular bajo una generalidad, en reconocer algo de una regla" (Gadamer, 1977, p. 62) y, el sentido ético de lo justo y lo correcto. De modo que la aplicación de esta capacidad requiere más del desarrollo de la sensibilidad y del gusto, que de la implementación mecánica o lógica de un procedimiento. La capacidad de juicio se puede plantear en términos de una exigencia generalizable. En razón de esto, se puede dirigir a cualquier individuo en el conjunto social en lo que se refiere a la capacidad de evaluar la relevancia de los eventos cotidianos y a la asunción de puntos de vista de acuerdo con la justicia y la corrección. Desde el punto de vista estético, más allá de la evaluación de perfección, entendida como conformidad con un ideal, la capacidad de juicio se enfoca a la congruencia interna. En este sentido, una ciuda- 
danía cosmopolita, como la que plantea Nussbaum (2005; 2010), se anclaría tanto en el sentido comunitario como en la capacidad de juicio en la que este se manifiesta:

Todo el mundo tiene tanto "sentido común», es decir, capacidad de juzgar, como para que se le pueda pedir muestra de su "sentido comunitario», de una auténtica solidaridad ética y ciudadana, lo que quiere decir tanto como que se le pueda atribuir la capacidad de juzgar sobre lo justo e injusto, y la preocupación por el «beneficio común» (Gadamer, 1977, p. 63).

Gadamer amplía, a partir de Kant, la capacidad de juicio al convertir en obligación "la abstracción de las condiciones subjetivas del propio juicio y ponerse en el punto de vista del otro" y al volver incondicional la exigencia de la conciencia moral de no "eximirse a sí misma de la apelación al juicio de los demás” (1977, p. 64). Sin embargo, reconoce que en Kant esta obligación incondicional se relaciona más con un imperativo categórico que con el sentido común, por lo que este sería simplemente una etapa previa del entendimiento. Para Gadamer, en Kant solo se entiende como sentido común la capacidad de gusto sensible, es decir, el gusto en un sentido más moral que estético. Reconoce en el "gusto" un "modo de conocer" que se asemeja a un sentido (1977, p. 68). El poder cognoscitivo del gusto está ligado a las manifestaciones concretas y no es susceptible de generalizaciones empíricas ni referencias conceptuales: "tanto el gusto como la capacidad de juicio son maneras de juzgar lo individual por referencia a un todo, si concuerda con todo lo demás, esto es, si es "adecuado»" (1977, p. 70).

Considera que a partir del pensamiento de B. Gracian y del progresivo empoderamiento de la persona común a nivel social se consolida un ideal de humanidad auténtica y de buena sociedad. En la humanidad auténtica el ser humano "alcanza en todas las cosas de la vida y de la sociedad la justa libertad de la distancia, de modo que sepa distinguir y elegir con superioridad y conciencia" (Gadamer, 1977, p. 67). La buena sociedad, a su vez, se reconoce y legitima "por la comunidad de sus juicios, o mejor dicho, por el hecho de que acierte a erigirse por encima de la estupidez de los intereses y de la privatización de las preferencias, planteando la pretensión de juzgar" (Gadamer, 1977, p. 67-68). 
A semejanza de los sentidos, el gusto carece de razonamientos previos y, aunque se relaciona con la moda no se limita a ésta, sino que se manifiesta como "una capacidad de discernimiento espiritual" (Gadamer, 1977, p. 69). La moda, de hecho, simplemente obedece a una generalización de lo que 'todo el mundo' hace, pero, más bien "forma parte también del concepto del gusto el mantener una mesura dentro de la moda, el no seguir a ciegas sus exigencias cambiantes y el mantener siempre en acción el propio juicio" (Gadamer, 1977, p.69). Por tanto, el gusto implica una capacidad de juicio estético en la que el caso particular aporta correcciones éticas a los baremos y a las reglas del juicio. De modo que el buen gusto constituye de hecho un momento ineludible de toda decisión moral:

Aquel a quien lo injusto le repugna como ataque a su gusto, es también el que posee la más elevada seguridad en la aceptación de lo bueno y en el rechazo de lo malo, una seguridad tan firme como la del más vital de nuestros sentidos, el que acepta o rechaza el alimento (Gadamer, 1977, p. 72).

En conjunto, la recuperación de los conceptos hasta aquí tratados formación, sensus communis, capacidad de juicio, gusto- reestablecen para las humanidades un campo de fundamentación en el que la retórica juega un papel central en la valoración de la capacidad heurística de la ética y de la estética y en el que el ejercicio de la prudencia permite razonar a partir de datos concretos e implicaciones contextuales. Aunque esta recuperación pueda ser vista legítimamente como una ampliación de la ética y la estética desde su originaria tradición humanista, implica igualmente una proyección lingüística al reconocer que el conocimiento humano no está restringido al uso teórico y práctico de la razón, sino que se funda en la pragmática del lenguaje, en especial en lo que tiene que ver con los asuntos humanos. Schaeffer, siguiendo a Gadamer, muestra cómo esta referencia frontal al sensus communis tiene su eje en el giro lingüístico: "Sensus communis is grounded in the language, literature, and institutions of a community and relates to the community's political and social world, a relation that is consensual and concrete" (1990, p. 150). (TdA: El sensus communis está fundado en el lenguaje, la literatura y las instituciones de una comunidad y relaciona a la comunidad política y al mundo social, una relación que es consensual y concreta). 
Una rápida revisión de lo expuesto ayuda a comprender que la educación propuesta por las humanidades tiene en cuenta muchos elementos que una capacitación técnica o una instrucción memorista dejan de lado o suprimen por completo:

Una cultura que otorga a la ciencia un puesto eminente y, por tanto, también a la tecnología basada en ella, nunca puede rebasar el marco más amplio que envuelve a la humanidad. La retórica y la hermenéutica tiene un puesto indiscutible y global en este marco más amplio" (Gadamer, 1992, p. 281).

De hecho, el recurso reiterado al método científico y a la lógica de la ciencia, si bien resuelve gran parte de los problemas no puede utilizarse para precisar los problemas humanos cotidianos que giran en torno a lo que la persona común sabe, entiende y busca. Por esto Gadamer insiste en que el recurso a las humanidades, y en especial a la retórica, permiten un abordaje alternativo de las exigencias de la vida cotidiana:

La ciencia que es poder y que reclama poseer algo, es tan solo una forma de saber. Pero hay otra forma más, y esa otra es la que yo desearía defender: encontrar la palabra correcta en el instante adecuado, eso que es la precisión misma. Tal era el antiguo y honorable concepto de la retórica (2001, p. 378).

Dentro de estos elementos se considera la reflexión sobre la formación en sí misma (Lat. formatio; Al. Bildung), el cultivo del sentido común (sensus communis), el desarrollo de la capacidad juicio (ético y estético) y la valoración del gusto. Estos elementos, en conjunto, suponen una comprensión lingüística de la realidad humana, asumida expresamente por la retórica y que tienen su correlato en otras disciplinas humanistas (hermenéutica, dialéctica, poética, gramática). Ellas estudian estas comprensiones lingüísticas y dan cuenta de la ratio de los asuntos humanos allí implicados. En este sentido, la retórica, al igual que otras disciplinas humanistas es "una actividad mediadora general que se da mucho más en el trato de la vida diaria que en el contexto de la ciencia" (Gadamer, 1992, p. 286).

Los elementos que una formación técnica o científica deja de lado, conducen a un cultivo del lenguaje que de una u otra manera excede o precede el uso científico y se ancla con gran énfasis en la vida cotidiana, en el arte y en la cultura. De hecho, la retórica no es "un asunto exclu- 
sivo de los especialistas. Aunque el arte de hablar utilice unos recursos técnicos especiales que se pueden aprender, no deja de ser en el fondo una capacidad natural del ser humano" (Gadamer, 1992, p. 277-288). El lenguaje, como un hecho social constitutivo, precede al hablante particular y, por lo mismo, precede a cualquier arte o técnica del habla. Este emplazamiento del lenguaje en el conocimiento humano no se agota ni en la gramática lingüística ni en la dialéctica lógica que han gozado del favor de la academia en los últimos dos siglos, sino que remite al arte de la palabra persuasiva o retórica que permite articular no solo las artes del discurso (gramática y dialéctica), sino que articula esas artes con la competencia comunicativa que hace posible los actos del habla y la racionalidad comunicativa.

\section{El cultivo de lo humano y la gratuidad del bien}

A lo largo de los siglos XX-XXI, dos grandes orientaciones del conocimiento humano han reclamado su primacía sobre la manera como se debe configurar la educación en general: una, centrada en el reconocimiento de lo humano y, la otra, centrada en la instrucción técnica. Como lo ha hecho evidente Nussbaum, desde mediados del siglo pasado se ha impuesto, cada vez más, la primacía de modelos educativos que se inclinan por el fortalecimiento de la capacidad productiva de las naciones, frente a otros modelos educativos que enfatizan más en el desarrollo humano centrado en la educación integral, en la ciudadanía y en la solidaridad universal (2005; 2010; 2012). Esta situación anima el debate educativo y abre un espacio de reflexión necesario sobre el fundamento, justificación y finalidad de cualquier iniciativa en el campo de la educación (Martínez Boom, 2004; Ordine, 2013). Sin embargo, este espacio de reflexión con frecuencia se desestima ya que la lógica imperante glorifica la instrucción lucrativa y banaliza el cultivo de las humanidades.

Como agudamente lo analiza M. Nussbaum en varias de sus obras (2005; 2010; 2012), el afán de lucro hace prevalecer el interés por una educación tecnificada, de utilidad obvia e inmediata, sobre otro tipo de saberes como los que proponen las humanidades, ya que éstos se ocupan del cultivo de lo que humaniza al ser humano a nivel individual y social. En consecuencia, el escaso interés que en la educación supe- 
rior suscita el aprendizaje de las humanidades hace que saberes como la retórica, la dialéctica, la gramática, la poética y la filosofía se presenten como materias opcionales o institucionales de escaso interés práctico y de aún menor relación con la disciplina profesional que se ha elegido. Ordine realiza en sus obras un agudo análisis de estas tendencias, en particular en el ámbito europeo:

En los próximos años habrá que esforzarse para salvar de esta deriva utilitarista no solo la ciencia, la escuela y la universidad, sino que también todo lo que llamamos cultura. Habrá que resistir a la obsolescencia programada de la enseñanza, de la investigación científica, de los clásicos y de los bienes culturales. Porque sabotear la cultura y la enseńanza significa sabotear el futuro de la humanidad (2013, p. 111).

Esta situación -de acuerdo a la investigación de M. Nussbaum-se puede constatar a nivel mundial tanto en la educación superior en general, como en la formación profesional de base humanista en particular $(2005 ; 2010 ; 2012)$. La preocupación es más notoria respecto a aquellas disciplinas que se fundan en saberes discursivos y que tiene como base la cultura de las humanidades, del arte, de las letras y de las ciencias humanas y sociales. Cabría preguntarse si una instrucción de índole técnica se ajustaría a las necesidades y estatutos de saberes que requieren más de la reflexión, del diálogo, de la discusión y de la deliberación, o si por el contrario conviene más cultivar el arte de la palabra allí donde los datos no pueden ser concluyentes ni las soluciones técnicas son decisivas. En todo caso, una recuperación del arte de la palabra pasa necesariamente por el cultivo de la formación humanista. Es decir, una recuperación de la retórica como facultad en general, o como arte en particular, pasa por una revaloración de las humanidades, del discurso, del diálogo, es decir, de 'lo humano'.

La propuesta de M. Nussbaum que ahora se presenta de manera esquemática, propende por la recuperación de una educación humanista básica para toda la educación escolarizada y por el cultivo de unas habilidades básicas que, según su parecer, fortalecen los fundamentos de las sociedades democráticas, pluralistas e inclusivas en las que pretenden vivir la mayor parte de las naciones en la situación actual. En el conjunto de estas habilidades se destaca la capacidad argumentativa que, según su punto de vista, permite el desarrollo de la autonomía racional de 
personas y comunidades como fundamente del cultivo de las facultades morales. Al mismo tiempo, muestra cómo esa educación humanista se ve amenazada tanto por los modelos preceptivistas de la educación conservadora, como por los modelos receptivistas de la educación instruccionista orientada unilateralmente hacia el lucro.

Desde los tiempos de la academia platónica y del liceo aristotélico, la educación inspirada en el cultivo de lo humano se ha perfilado como un espacio fundamental para la democracia y para la libertad de pensamiento. Esta educación prepara a cada integrante de la sociedad como individuo consciente, ciudadano cosmopolita y persona solidaria. Sin embargo, como lo advierte Nussbaum, este tipo de educación que prioriza el valor de la persona corre el riesgo de verse desplazada por la urgencia de asegurar una rentabilidad: "corremos el riesgo de perder ciertos valores de importancia enorme para el futuro de la democracia, sobre todo en una época de preocupaciones religiosas y económicas" (2010, p. 25).

Como lo ha señalado M. Nussbaum, una de las razones del éxito alcanzado en la educación orientada hacia la instrucción técnica ha sido el prestigio del que ha gozado por más de un siglo y medio el modelo del crecimiento económico, frente a otros modelos de crecimiento social que enfatizan el desarrollo humano o la armonía con el medio ambiente $(2005 ; 2012)$. Aunque este prestigio ha sido bien ganado, en cuanto que un alto nivel de instrucción técnica contribuye de manera clara al crecimiento industrial y económico de un país, sin embargo, cualquier proyecto de democracia requiere no solo de un alto índice del PIB, sino del desarrollo humano de los individuos en vistas a una adecuada participación política y a una equilibrada interacción social. De todos modos, el interés por una economía sólida y una empresa próspera "también se nutre de las artes y las humanidades para fomentar un clima de creatividad innovadora y de administración responsable y creativa de los recursos" (Nusbaaum, 2010, p. 30).

Para conjurar el riesgo de reducir la educación a una instrucción técnica, esta autora propone tres habilidades que se deben desarrollar simultáneamente dentro de un enfoque humanista en una visión democrática: el pensamiento crítico, la cultura cosmopolita y la imagi- 
nación compasiva (cf. Nussbaum, 2005, p. 28-29). El valor de estas habilidades radica, ante todo, en su potencial para favorecer la formación integral y para fortalecer la democracia por medio del cultivo de modos de pensar alternativos, abiertos y altruistas. Por una parte, estas habilidades se enmarcan dentro de una comprensión más amplia de "capacidades humanas» ligadas a derechos fundamentales que garantizan el desarrollo individual y social. Por otra parte, estas habilidades se vinculan dentro de una tradición humanista que promueve la educación integral de la persona. En conjunto, el énfasis en estas capacidades permite que una propuesta educativa sea verdaderamente democrática, ya que, de lo contrario, con un interés exclusivo en la renta o el lucro, "los estados nacionales y sus sistemas de educación están descartando sin advertirlo ciertas aptitudes que son necesarias para mantener viva la democracia" (Nussbaum, 2010, p. 20).

En este contexto de fortalecimiento de la democracia, las capacidades se entienden no solo como unas potencialidades reales de las personas, sino que también se consideran unas oportunidades efectivas de desarrollo personal ligadas a derechos fundamentales (Nusbaum, 2012, p. 14). Esto, por supuesto, dentro de una concepción integral de la educación en la que se contempla que "la educación no solo nos prepara para la ciudadanía, sino también para el trabajo y, sobre todo, para darle sentido a nuestra vida" (Nussbaum, 2010, p. 28). Dentro de este enfoque de las tres habilidades la autora destaca "la importancia de la argumentación" como una capacidad central de las tres habilidades y como un aprendizaje que no ocurre espontáneamente, sino que requiere del acompańamiento de una persona experta y de unas orientaciones institucionales que lo favorezcan y valoren (cf. Nussbaum, 2010, pp. 75-11).

Aunque la filosofía y la literatura proveen magnificas herramientas para comprender la argumentación, es el arte retórico entendido dentro del conjunto de las humanidades, el que configura esa capacidad para valorar lo humano tanto en el dialogo, la discusión y el debate, como en las instancias en las que el habla argumentativa resulta relevante, como el tribunal, la asamblea, la plaza pública y la academia. En otras palabras, el estudio de la argumentación resulta un elemento fundamental no solo para el pensamiento crítico y para la solidaridad, sino sobre 
todo para el ejercicio de cualquier profesión de base humanista que se ocupe del ejercicio de saberes discursivos.

En suma, el enfoque humanista de la educación se pregunta por la capacidad de una persona que ha recibido una educación básica o incluso superior de interactuar críticamente desde formas concertadas y socialmente relevantes de comunicación. O para colocarlo en las palabras de Nussbaum, se requiere educar para una cultura ciudadana, democrática y libertaria y no únicamente para la comercialización o el lucro: "distraídos por la búsqueda de riqueza, nos inclinamos cada vez más por esperar que nuestros centros educativos formen personas aptas para generar renta en lugar de ciudadanos reflexivos" (2005, p. 187).

Figura 2. Las habilidades centrales según M. Nussbaum.

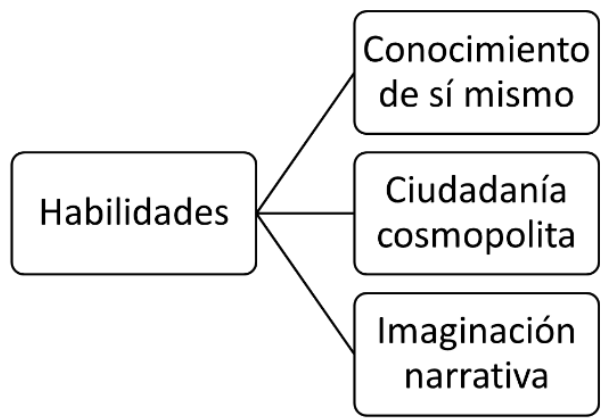

Fuente: Los autores, 2017.

Esas tres habilidades, según Nussbaum, giran sobre un modo de pensar alternativo que no se limita a lo tecnológico o a lo estratégico, sino que cultivan una gama amplia de capacidades que fortalecen la autonomía, el pluralismo y la solidaridad, valores éstos que, en gran medida, coinciden con la tradición humanista.

\section{El conocimiento de sí mismo}

Para Nussbaum, el conocimiento de sí mismo, conjugado con la ciudadanía mundial y con la imaginación narrativa, constituye el punto de partida de la educación del ser humano en la sociedad actual. Prevalece la necesidad de cultivar una capacidad básica de raciocinio, el pensamiento crítico deliberativo, sobre una instrucción técnica o sobre la 
erudición filológica. Con ello se reivindica la vinculación de la vida cotidiana en una sociedad democrática con la educación superior y nos solo la necesidad que tiene cualquier sociedad moderna de institucionalizar el aprendizaje. Se sigue el ideal mayéutico de fundamentar la acción sobre una capacidad autónoma de reflexión y no sobre la costumbre o sobre opiniones bien acreditadas. La primera habilidad es el conocimiento de sí mismo que, para esta autora, sería la capacidad de servirse del propio entendimiento, al estilo socrático, para decidir en todos los aspectos de la existencia humana, sin someterse servilmente a cualquier autoridad, costumbre o moda. En este sentido, se requiere el cultivo de un pensamiento crítico que permita pasar de la respuesta reactiva básica, a una respuesta reflexiva que no se quede en los hechos, datos o primeras impresiones, sino que cultive la búsqueda de constantes, patrones o repertorios.

En este sentido, la autora propone la figura de Sócrates como alguien que:

Defendió su actividad sobre la base de que la democracia necesita ciudadanos que puedan pensar por sí mismos, en lugar de simplemente remitirse a la opinión de las autoridades; que puedan razonar juntos sobre sus opciones, en lugar de limitarse a intercambiar argumentos y contraargumentos (Nussbaum, 2005, p. 28).

Esta habilidad de pensar por sí mismo sería indispensable en una nación democrática que se propone como fin la realización del ciudadano y en una sociedad que tiene el conocimiento como el más alto valor: "con el fin de fomentar una democracia que sea reflexiva, y no un mero mundo mercantil de grupos de interés en competencia, una democracia que verdaderamente tome en consideración el bien común" (Nussbaum, 2005, p. 39). La autora propone cuatro características básicas para desarrollar el conocimiento de sí mismo: universal, adaptable, pluralista y racional (2005, p. 54). Estas características garantizarían un examen crítico de las costumbres, hábitos y prejuicios para que el ejercicio de las libertades sustantivas adquiera un estatus y un sentido más allá de una simple reivindicación formal o de una convención social carente de contenido teórico o práctico. Asimismo, estas características fortalecerían la ciudadanía democrática en cuanto favorecen un ejercicio libre y efectivo de los propios derechos y obligaciones. 
Figura 3. Cuatro características del conocimiento de sí mismo en Nussbaum.

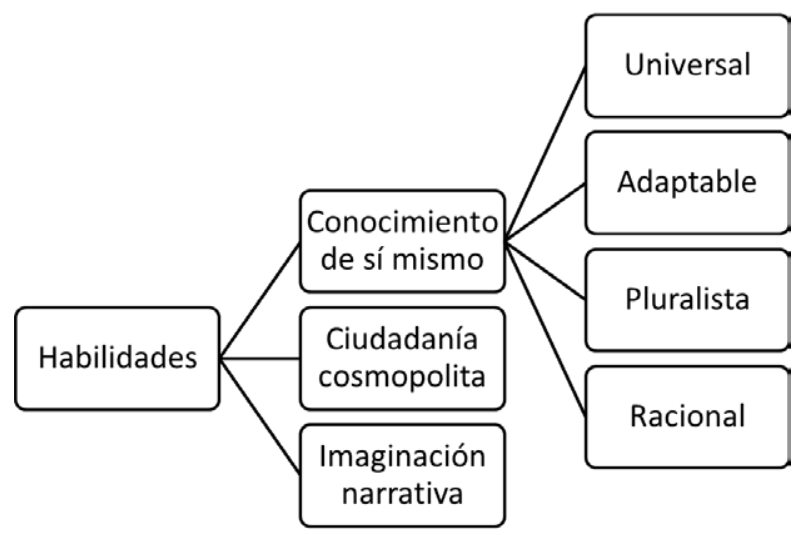

Fuente: Los autores 2017.

La universalidad del conocimiento de sí mismo, se refiere tanto a unas habilidades básicas para todas las personas, como a la posibilidad de extenderlo a toda la educación escolarizada. Como habilidades básicas universales se considera la lectoescritura, la matemática y la cultura general. La posibilidad de extenderlo a toda la educación se refiere a que todo tipo educación posterior a la básica secundaria debe contar con una formación para la democracia, para la ciudadanía y para la solidaridad social. La universalidad, a su vez, requiere ser matizada por las siguientes características, de modo que los valores universales tengan expresión y arraigo en lo particular. La adaptabilidad, si bien las habilidades básicas son universalizables, es necesario desarrollar una capacidad reflexiva que responda a los desafíos de cada circunstancia y de cada contexto particular, asimismo se requiere que sea personalizable y adaptable a las necesidades sociales o nacionales. De lo contrario, se corre el riesgo de imponer un currículo universal que ignore la realidad que pretende modificar, porque si bien las metas universales son compartidas, los puntos de partida son diversos, por lo que "se requieren muchos y diferentes enfoques curriculares” (Nussbaum, 2005, p. 55).

El pluralismo, pretende integrar todos los aspectos de la existencia individual y social sin uniformarlos. Obliga a enfrentar diferentes modos de hacer las cosas en prácticas donde se considera que los propios procedimientos son neutrales, necesarios y naturales. Y este pluralismo conlleva 
un conflicto cognitivo con culturas, prácticas y costumbres que difieren notablemente de los que en una cultura se considera 'lo natural' o, peor aún, 'lo racional'. La capacidad de razonamiento práctico, se asemeja al concepto de racionalidad comunicativa de Habermas, pues la autora relativiza mucho el peso de la autoridad, especialmente la que provine de los libros. Ni los textos escritos sustituyen la reflexión genuina, ni la información elimina la formación, por lo que sugiere "aclarar las cosas, no por medio del conocimiento especializado, sino a través del razonamiento" (Nussbaum, 2005, p. 70). La capacidad reflexiva, es, en últimas, el eje del pensamiento crítico, mientras las características precedentes - universalidad, adaptabilidad y pluralidad- constituyen condiciones previas. Como se trata más adelante, la autora retoma esta propuesta que enfatiza más las capacidades, entendidas como libertades sustantivas, que las informaciones, los contenidos o las tradiciones.

Vista en conjunto, esta habilidad del conocimiento de sí mismo depende básicamente de lo que en la tradición aristotélica se denomina razonamiento dialéctico, es decir, de la capacidad de reflexionar a partir de premisas que dependen de creencias, opiniones y suposiciones generalizadas (Aristóteles, 1982, p. 90; Top. 100a, 30-31; 100b, 22-24). Este tipo de razonamiento se utiliza tanto para someter a crítica las costumbres, hábitos y prejuicios, como para llegar a conclusiones socialmente relevantes que permitan justificar o fundamentar una determinada práctica, procedimiento o reflexión. En la ciudadanía, en la democracia y en la academia se requiere de procesos de pensamiento, como el razonamiento dialéctico, que se ocupen de la opinión pública, de los acontecimientos probables y de las interacciones sociales con el fin de establecer puntos de referencia. En palabras de Nussbaum "para desenmascarar el prejuicio y para asegurar la justicia necesitamos de la argumentación, una herramienta esencial de la libertad cívica" (2005, p. 40). En consecuencia, el cultivo de estos procesos de pensamiento y de procedimientos pragmáticos de análisis de las opiniones, de las decisiones y de los consensos no es una cuestión subsidiaria o complementaria de una formación humana básica, sino el núcleo mismo de ella, pues, como indica Nussbaum, "la exigencia de razones incide en la decisión que se tomará finalmente" (2005, p. 47). Esta propuesta, en torno a la centralidad de la argumentación para el pensamiento crítico, es profundizada mediante la consideración de las implicaciones 
de su implementación en el ámbito de la vida social, en general, y de su alcance en la educación formal, en especial. La siguiente habilidad, el cosmopolitismo, supone ya un ejercicio crítico del pensamiento y una capacidad de asumir creativamente las exigencias de un mundo cada vez más multicultural y globalizado y los desafíos de las llamadas sociedades del conocimiento.

La segunda habilidad es la ciudadanía universal o cosmopolitismo. Al igual que la anterior, la idea original está tomada de la cultura grecorromana, pero de la escuela cínica y de la escuela estoica. En esa época esta idea estaba dominada por el ideal de la comunidad de naciones

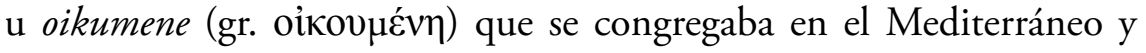
el Medio oriente. En la actualidad este ideal se presenta con nueva fuerza debido al fenómeno de la globalización, por el cual la interdependencia se hace más evidente debido a la ubicuidad de los medios masivos de comunicación, al comercio internacional y a las facilidades del transporte. También los problemas adquieren un carácter mundial y multinacional que afecta las realidades concretas de un modo que es absolutamente nuevo en la historia de la humanidad. La educación, "debería proporcionarnos los elementos necesarios para desenvolvernos de manera eficaz en ese diálogo multinacional, como ciudadanos del mundo" (Nussbaum, 2010, p. 114). De lo contrario, "lo más probable es que nuestras interacciones humanas se vean mediadas por normas tan lábiles como las del mercado, que concibe las vidas humanas principalmente como instrumentos para obtener ganancias" (Nussbaum, 2010, p. 114).

La tarea de educar personas que tengan conciencia de su ciudadanía universal parece interminable, sin embargo, comienza por la aplicación del pensamiento crítico a la superación de los clichés, estereotipos y miedos con los que se enfrenta una cultura con otra, incluso a las culturas que conviven dentro de la misma nación. Una educación acorde a las actuales circunstancias no puede hacer caso omiso de esta exigencia, pues las nuevas generaciones deben "entender tanto las diferencias que impiden la comprensión mutua entre grupos y naciones distintos como las necesidades y los intereses compartidos que le dan un rol protagónico a esa misma comprensión para la resolución de problemas en común" (Nussbaum, 2010, p. 115). 


\section{Los saberes necesarios}

Es oportuno preguntarse ¿qué necesita saber un profesional y de qué modo la educación superior lo prepara para desempeñarse en un nuevo rol o en un nuevo contexto? Las respuestas, como es imaginable, no están ya elaboradas, sino que se fabrican teniendo en mente una democracia pluralista y una diversidad enorme de puntos de partida sociales, culturales e históricos. Subsisten, sin embargo, algunos puntos de referencia básicos relativos al desarrollo de la razón que modula la interacción social. A este respecto, Nussbaum enfatiza que "ninguna diferencia borra las exigencias básicas de la razón y de la capacidad moral que constituyen la base de la comunidad universal y la razón fundante de la lealtad a ella" (Nussbaum, 2005, p. 86). Las ventajas de un currículo que tenga en cuenta la diversidad de culturas, religiones y organizaciones redundarán en beneficio de una mayor capacidad y una mayor competencia de los profesionales. Como señala Nussbaum:

Cuando entendemos las innumerables maneras en que las personas pueden organizar sus vidas, seremos capaces de reconocer lo que es profundo y lo que es superficial de nuestras maneras de vivir y consideraremos que la única comunidad verdadera es la que abarca el mundo entero (2005, p.85).

A este propósito, se propone el estudio de las culturas y lenguas que conviven en un mismo país, el origen de los productos alimenticios y la existencia de numerosas tradiciones religiosas, incluso al interior de la misma religión o de la misma Iglesia. El estudio de la diversidad humana requiere de pensamiento crítico, imaginación e investigación en un ambiente de libertad de expresión, de aprendizaje cooperativo y de discusión. Aunado a esto se recomienda el estudio de las lenguas, en especial el dominio de una segunda lengua a partir del conocimiento de su cultura, literatura y música. Este estudio permite reconocer que otras culturas tienen otra comprensión del mundo y que cualquier traducción expresa de manera deficiente lo que otra lengua expresa de manera completa. Esta propuesta supone la adecuación del currículo, incluso el de pregrado, en torno a las habilidades básicas mencionadas y requiere que la educación, en especial la superior, cuente "con estructuras dedicadas a la educación humanística” (Nussbaum, 2010, p. 129). 
Esta ciudadanía universal requiere de una tercera habilidad llamada 'imaginación narrativa' que enlaza con las anteriores por cuanto exige que las personas cultiven la reflexión autónoma y la ciudadanía cosmopolita. Esta habilidad pone en evidencia la insuficiencia de la información, de lo fáctico y de la lógica para suscitar, por sí mismas, la empatía entre personas, culturas y naciones. Asimismo, supone que las personas han alcanzado, por una parte, cierto grado de competencia práctica o dominio personal que les permite desempeñarse con solvencia en su propio contexto; supo, por otra parte, que la persona es consciente de la necesidad de cooperación y solidaridad. Por ello, es importante, que en los planteamientos de las instituciones educativas se otorgue "un rol protagónico a las artes y a las humanidades en el programa curricular, cultivando un tipo de formación participativa que active y mejore la capacidad de ver el mundo a través de los ojos de otro ser humano" (Nussbaum, 2010, p. 132).

La imaginación narrativa es -en palabras de Nussbaum- "la capacidad de pensar cómo sería estar en el lugar de otra persona, de interpretar con inteligencia el relato de esa persona y de entender los sentimientos, los deseos y las expectativas que podría tener esa persona” (2010, p. 132). En esta misma línea, algunos autores plantean esta capacidad en términos de una competencia narrativa: "interactive processes, which allow us to perceive the feelings and intentions of others in their movements, gestures, facial expressions, and actions, feed into the development of more nuanced intersubjective understandings found in narrative practices" (Gallagher, 2012, p. 36). [TdA: procesos interactivos que nos permiten percibir los sentimientos e intenciones de otros en sus movimientos, gestos, expresiones faciales y acciones, nutren el desarrollo de unos entendimientos intersubjetivos más matizados encontrados en prácticas narrativas]. Esta habilidad para ponerse en el lugar del otro y comprender sus deseos y necesidades es el comienzo de la empatía y de la compasión. La empatía implica reconocer al otro diferente como igual a uno y la compasión implica "el reconocimiento de que otra persona, de algún modo similar a uno, ha sufrido una pena o desgracia importante por la que no se le debe culpar o solo en parte" (Nussbaum, 2005, p. 124). 
La imaginación narrativa, como recurso pedagógico para influir positivamente en el cultivo de la humanidad en el reducido espacio del aula y de la academia, propone acudir a la literatura y, en general, a las artes porque "cultivan poderes de la imaginación que son esenciales para la construcción de la ciudadanía” (Nussbaum, 2005, p. 118). La razón para ello radica en que "las artes cultivan las capacidades de juicio y sensibilidad que pueden y deben expresarse en las opciones de los ciudadanos" (Nussbaum, 2005, p. 118). Las artes, en especial la literatura, serían particularmente eficaces para expresar y representar las singularidades de la condición humana, no solo como han sido o son, sino sobre todo como pudieron haber sido o pueden llegar a ser. En otras palabras, "el cultivo de la comprensión constituye un elemento clave en las mejores concepciones modernas de la educación” (Nussbaum, 2010, p. 132).

Este cultivo de una "capacidad de imaginación receptiva" que propone Nussbaum se traduciría, ya no en el plano artístico, sino en el de la vida cotidiana, en aprender a acoger personas, particularmente aquellas que por alguna razón son diferentes, y en aprender a comprender sus opciones y motivos precisamente a partir de esa diferencia. Con ello, se potenciarían enormemente las capacidades de reflexión crítica y de ciudadanía universal por varias razones: porque esta capacidad permitiría que personas provenientes de otra cultura, religión o clase social fueran vistas como seres iguales que comparten unos problemas y oportunidades y no como potenciales amenazas; porque esta capacidad ayudaría a entender que las diferencias enriquecen la experiencia humana, pero, a la vez, dificultan el entendimiento ya que moldean las oportunidades que se le presentan a cualquier persona y forman los mundos internos que determinan su cosmovisión. Por lo que, en definitiva, el valor del cultivo de la imaginación narrativa sería precisamente el de permitir, al mismo tiempo, un ejercicio de sensibilización hacia la diversidad de la condición humana y de fortalecimiento de una cultura ciudadana solidaria. El cultivo de la imaginación narrativa, mediante un proceso gradual y diferenciado, ayudaría desde las primeras etapas de la vida a reconocer la vida interior de todas las cosas y de todos los seres y a fomentar la resonancia compasiva ante el otro. La ciudadanía cosmopolita solo es posible mediante el cultivo de estos sentimientos que constituyen la base de la interacción moral. En efecto, la habilidad 
de narrar y de escuchar narraciones estimula la capacidad de formular hipótesis sobre realidades internas que no son visibles inmediatamente $y$, al mismo tiempo, hace consciente las limitaciones que experimenta cada persona en el conocimiento de las realidades internas y externas. Con ello se busca desarrollar el respeto hacia la vida interior de las personas y a valorar las condiciones que hacen realidad la libertad y la felicidad humana.

En esto concuerda con Barthes (1993b) que ve en la literatura un saber universal, cosmopolita y contextualizado que tiende a ser más realista que la ciencia misma:

En una novela como Robinson Crusoe existe un saber histórico, geográfico, social (colonial), técnico, botánico, antropológico (Robinson pasa de la naturaleza a la cultura). Si por no sé qué exceso de socialismo o de barbarie todas nuestras disciplinas menos unas debieran ser expulsadas de la enseńanza, es la disciplina literaria la que debería ser salvada, porque todas las ciencias están presentes en el monumento literario. Por esto puede decirse que la literatura, cualesquiera fueren las escuelas en cuyo nombre se declare, es absoluta y categóricamente realista: ella es la realidad, o sea, el resplandor mismo de lo real. Empero, y en esto es verdaderamente enciclopédica, la literatura hace girar los saberes, ella no fija ni fetichiza a ninguno; les otorga un lugar indirecto, y este indirecto es precioso. Por un lado, permite designar unos saberes posibles —insospechados, incumplidos-: la literatura trabaja en los intersticios de la ciencia, siempre retrasada o adelantada con respecto a ella, semejante a la piedra de Bolonia, que irradia por la noche lo que ha almacenado durante el día, y mediante este fulgor indirecto ilumina al nuevo día que llega. La ciencia es basta, la vida es sutil, y para corregir esta distancia es que nos interesa la literatura. Por otro lado, el saber que ella moviliza jamás es ni completo ni final; la literatura no dice que sepa algo, sino que sabe de algo, o mejor aún: que ella les sabe algo, que les sabe mucho sobre los hombres (p. 124).

En este sentido, la autora destaca dos funciones que cumplen las artes en la educación escolarizada: "por un lado cultivan la capacidad lúdica y de empatía en modo más general y, por el otro, se enfocan en los puntos ciegos específicos de cada cultura” (Nussbaum, 2010, p. 147). El cultivo de la imaginación y de la comprensión resultan fundamentales para el diálogo crítico con las tradiciones, por cuanto proporciona una perspectiva acerca de la manera como en otras épocas, en otras circunstancias, en otros contextos o en otras culturas las personas dieron respuestas a sus problemas y de las razones por las cuales esas 
respuestas pueden resultar inadecuadas en otras situaciones. Aunque la literatura y, en general el arte no se oriente directamente a un cambio político, sí tienen un efecto sobre el mantenimiento, crítica o reforma de los valores morales que sustentan una determinada opción política.

En este enfoque, la lectura no solo es una competencia cognitiva, sino que hace parte del equipamiento necesario para la vida social en una cultura democrática: "este compromiso con la construcción de un mundo social y de una comunidad deliberante que reflexione críticamente sobre él es lo que torna tan fascinante y tan urgente la aventura de leer" (Nussbaum, 2005, p. 139). En este sentido, la elección de un conjunto de obras literarias que en algún momento pudieron ser marginales y que representan diversas facetas de la realidad humana y la adopción de perspectivas de análisis que resalten las realidades y los valores humanos contribuirían a potenciar el pensamiento crítico y el sentido de una ciudadanía cosmopolita: "si la literatura es una representación de las posibilidades humanas, las obras de literatura que escogemos inevitablemente responderán a nuestro sentido de quiénes somos y quiénes podríamos ser, y lo desarrollarán más aún” (Nussbaum, 2005, p. 142). Pero, en todo esto se debe cuidar que los puntos de vista y los intereses representen la diversidad humana: "todos aprendemos más de un currículo que contiene desacuerdos y diferencias, donde hay una interacción de puntos de vista opuestos" (Nussbaum, 2005, p. 143). El cultivo de la 'imaginación narrativa' evidencia, en últimas, la posibilidad de incluir la academia en la configuración de una democracia pluralista, universalista y solidaria.

Esta visión de la educación humanista insiste en que "todos los ciudadanos necesitan entender las diferencias con las que deben convivir" (Nussbaum, 2005, p. 145), ya que la ideología neocapitalista amenaza la democracia al reducirla al libre mercado. Desde la perspectiva puramente lucrativa, contraria a la visión humanista, las diferencias en una sociedad (raza, clase, sexo, entre otros) solo son el motor de una lucha sin acuerdos ni entendimientos mutuos entre las partes que se enfrentan, pues la "democracia no es más que un mercado de grupos de interés en competencia, sin objetivos ni metas comunes en torno a las cuales se pueda deliberar racionalmente" (Nussbaum, 2005, p. 146). La literatura, y en general las artes, tienen la posibilidad de servir de 
"medio de expansión de afinidades que la vida real no puede cultivar de modo suficiente" (Nussbaum, 2005, p. 147).

Este notable interés - de acuerdo con la propuesta de Nussbaum- por la imaginación narrativa como medio para cultivar la capacidad de comprensión por medio de la literatura, las artes y las humanidades se orienta al fortalecimiento de la apertura a la alteridad con el fin de contrarrestar el excesivo centramiento en los intereses individualistas que promueve el capitalismo neoliberal. En efecto, la imaginación narrativa es la capacidad de pensar a partir del lugar del otro, de escuchar e interpretar con empatía su relato y de entender que posee una interioridad que no se reduce a su fuerza laboral o a su clase social. Esta habilidad permite el cultivo de la capacidad de comprensión que, para la autora, "constituye un elemento clave en las mejores concepciones modernas de la educación para la democracia” (Nussbaum, 2010, p. 132). Esta capacidad supone el desarrollo de la empatía y el interés por las otras personas, lo que requiere el fortalecimiento de la autonomía, la solidaridad y la libertad. De lo contrario, es probable que la alienación cultural, el utilitarismo y el consumismo se erijan como el único entendimiento posible del mundo, de la sociedad y de la persona misma.

\section{La educación artística}

Para procurar una educación integral se exaltan las potencialidades de una educación artística que favorezca una ciudadanía democrática. De hecho, la práctica de las artes permite que las personas excluidas, los temas prohibidos y las realidades invisibilizadas aparezcan en el imaginario, al menos como figuras o estereotipos y permitan evidenciar los puntos ciegos de cada cultura, clase, nación o religión. El arte permite expresar de manera sutil y matizada las realidades que pueden contrariar las expectativas de la cultura dominante y, al mismo tiempo, ayudar a tomar conciencia de los puntos ciegos que se oscurecen en cada situación. Asimismo, permiten introducir de manera perspicaz puntos de vista normativos en los que se ponderen los ideales "acerca del modo como deben relacionarse entre sí los seres humanos" (Nussbaum, 2010, p. 147). Estas consideraciones se pueden extender, mutatis mutandi, al deporte, al juego recreativo atendiendo a las particularidades de cada una de estas manifestaciones en la cultura local y nacional. 
Este énfasis en la formación artística, resulta de particular interés la retórica, como un arte adecuado parar desarrollar los espacios potenciales de interacción social deliberativa y visibilizar los puntos ciegos que en cada cultura obstaculizan un diálogo profundo, una discusión abierta y un debate honesto. En el caso particular del arte retórico, la perspectiva normativa vendría por las condiciones para una comunicación razonable que han investigado R. Alexy en el campo del derecho y J. Habermas en el campo de la sociología. En conjunto, estas tres habilidades -pensamiento crítico, cultura cosmopolita e imaginación narrativa- se presentan como un modelo de formación humanista que se adecúa a las exigencias de una sociedad pluralista de orientación democrática. Vistas de este modo, las tres habilidades aparecen ligadas a la formación integral de la persona, a la educación para una ciudadanía cosmopolita y a la sensibilización ante el sufrimiento humano.

Es claro que para Nussbaum, y para otros autores que conceden importancia a las humanidades, el tipo de formación que proporciona el pensamiento crítico, la indagación deliberativa y el análisis crítico de la argumentación es fundamental no solo para el desempeño de una profesión, sino que se relaciona directamente con el ejercicio responsable de la ciudadanía y con el cultivo integral de los aspectos más relevantes de la vida humana. En efecto, las humanidades constituyen la base de las profesiones ligadas al conocimiento de lo humano, en especial de las relacionadas con el derecho, la filosofía y la teología, y contribuyen de manera explícita y específica a la formación integral de la persona.

En este trasfondo se profundizan algunas disciplinas particulares como la dialéctica, la gramática y la retórica, con el fin de prepararse para el ejercicio de la profesión en la sociedad, así como para participar de manera libre, consciente y cualificada en la democracia. El profesional del área de las humanidades no solo ejerce el campo particular de su disciplina, sino que, es ante todo, una persona íntegra y un ciudadano responsable. El desarrollo de las habilidades del pensamiento crítico, de la ciudadanía cosmopolita y de la imaginación narrativa le permiten adentrarse en las exigencias de la vida profesional y social teniendo como eje valores como la solidaridad, la justicia y la libertad. Igualmente, resulta claro que las tres habilidades en su conjunto giran en torno al lenguaje deliberativo, fundamentada en el pensamiento crítico, 
en la solidaridad humana y en la capacidad de imaginar otros mundos posibles y otras realidades humanas.

Según la autora, la formación humanista se orienta al fortalecimiento de valores como la autonomía, la libertad, la igualdad y la solidaridad que resultan esenciales para la orientación democrática de las sociedades y se opone a diversas regresiones del neoconservadurismo, del mercantilismo y del escepticismo. En su opinión:

Con el fin de fomentar una democracia que sea reflexiva y deliberante, y no un mero mundo mercantil de grupos de interés en competencia, una democracia que verdaderamente tome en consideración el bien común, debemos producir ciudadanos que tengan la capacidad socrática de razonar acerca de sus creencias (Nussbaum, 2005, p. 40).

\section{El fundamento de la formación humana}

Las diversas propuestas humanistas que se han presentado constituyen, más una reflexión sobre los problemas inherentes a la condición humana, que una reacción ante los desafíos de un mundo sumergido en las tecnologías de la información. La humanística ha asumido como propias las tareas de la formación humana, de la reflexión constante sobre los valores, del cultivo de las virtudes y de otras semejantes. Para ello, se necesita más el desarrollo de una capacidad reflexiva y dialogal que una ardua recopilación exhaustiva de datos. En las humanidades son más importantes las preguntas y los cuestionamientos que las respuestas inmediatas o las soluciones meramente tecnológicas. Las humanidades insisten en que, en todos estos problemas, la formación de la capacidad de acción y de discurso juega un rol muy importante, no solo en la búsqueda de respuestas a los desafíos que lanzan estos problemas, sino sobre todo en la comprensión de las implicaciones de cualquier alternativa o solución a esos problemas.

$\mathrm{Al}$ examinar en conjunto las propuestas planteadas se puede ver que resultan, al menos, dos maneras de afrontar los desafíos de la educación. Uno, confía la educación a un sistema escolarizado que mediante un proceso jerarquizado y gradual instruye a los individuos para la supervivencia, el trabajo y la convivencia social (cf. Tedesco, 2000, pp. 29-53). Esta solución al problema de la educación, sin embargo, se queda mera- 
mente en el nivel funcional o meramente técnico que, aunque necesario en la sociedad actual, es insuficiente para la formación personal, el ejercicio de la ciudadanía y el cultivo de la solidaridad. El otro, depende de la orientación humanista y considera que la educación debe ser integradora, esto es, que permita a las personas el desarrollo de sus potencialidades y que a la vez los cualifique para las labores cotidianas y la actividad productiva.

El primer enfoque giraría en torno al concepto de instrucción o 'educación para el trabajo’ y se comprendería en términos de competencias, o en su defecto, de objetivos y de logros. El segundo, por el contrario, se concentra en el concepto de formación y se comprende en términos de capacidades, virtudes y valores. En el primero, lo esencial es adquirir un conjunto de habilidades y destrezas, debidamente evaluadas y certificadas que garantizarían un desempeño en el ámbito de una empresa, de una institución o en el emprendimiento individual. En el segundo, lo fundamental se orienta al cultivo de la propia humanidad mediante la reflexión, el arte y la literatura. En el primero se contempla al individuo como un empleado competente, un profesional excelente o un creativo innovador. En el segundo, se contempla al individuo como una persona que interactúa en un grupo humano (comunidad) y que hace parte de una organización política como ciudadano.

En consecuencia, en el primero, se enfatiza el desarrollo de habilidades que configuren una competencia productiva acorde con las necesidades del mercado empresarial. En el caso particular de la habilidad de comunicarse se confía a la adquisición de unas habilidades del lenguaje o a una competencia comunicativa. En el segundo, se enfatiza en la capacidad de cuidar de sí, de los otros y del planeta, de desarrollar la reflexión y la creatividad ante los problemas particulares y universales y, sobre todo, a interactuar en el ámbito público mediante la acción y el discurso. Se enfatiza en este enfoque en que la escucha, el diálogo y la discusión constituyen el eje de la existencia humana y que se requiere de un cultivo de las artes sermocinales para constituirse en un auténtico ser

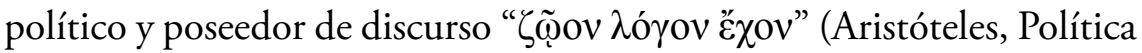
1253a 1-18; cf. Peri Hermeneias, I; EN I, 3). 
La preeminencia del enfoque utilitario, funcionalista o lucrativo en la educación, sobre otros enfoques distintos ya ha sido señalado por diversos autores (Ordine; Nussbaum; Martínez Boom). Esto ha conducido, por supuesto, a una erosión del enfoque humanista que recibe una atención marginal, incluso en disciplinas que tradicionalmente estaban ligados a él. Por ahora, se puede solo enfatizar en que, si bien la educación humanista se la presenta como un enfoque contracultural, con frecuencia relacionado con modelos tradicionales o, incluso, con enseńanzas obsoletas, todavía tiene mucho que decir, en especial en saberes y profesiones ligadas al discurso de las humanidades, las artes, las letras y las ciencias humanas y sociales.

Las razones para este ominoso olvido son muchas y variadas, por ahora basta señalar que, según $M$. Nussbaum, la desmedida preeminencia que tiene el aprendizaje lucrativo sobre el cultivo del humanismo y la consiguiente pérdida de significado de las humanidades y de las artes y letras en la educación en general y, en especial, en la educación superior (Nusbaum, 2005; 2010; 2012). Otra razón, no menos importante, sería atribuible a la sustitución generalizada que experimenta el discurso en la vida cotidiana en favor de informaciones fragmentarias, como descarnadamente la retrata $\mathrm{H}$. Arendt al estudiar la condición humana (2005). La pérdida del arte de la palabra se debe a la epidémica carencia de auténtico diálogo en la vida cotidiana, como lo seńala profusamente H-G. Gadamer en su obra (1977; 2000). Por cualquiera de estas razones, el arte del discurso ha perdido su lugar en la cultura actual y, por ende, su centralidad en la educación superior, en especial en la formación humanista.

La raíz grecorromana y, luego, judeocristiana acentuó la noción del ser humano como un ser en trasformación, una creatura que irrumpe en la naturaleza y da lugar a un mundo. Por ello, se resaltaron los conceptos de paidea como camino de formación ciudadana en la cultura griega y de humanitas como itinerario de la vita activa en la cultura romana. Conceptos que fueron retomados por Vico en su reflexión sobre los currículos (studiorum ratione) para proponer unos modelos de conocimiento y acción aplicados a los asuntos humanos, opuestos al cartesianismo de la época. 
Este énfasis en la necesidad de la formación integral de la persona también es reconocido en los ámbitos en los que la formación científica no es reducida a la capacitación técnica, como ocurre con G. Charpak, premio nobel de física, que al presentar sus reflexiones sobre la libertad recuerda que "es evidente que la libertad interior es una conquista de cada instante" (Charpak \& Omnes, 2005, p. 132). Y en ello juega un papel esencial el autoexamen racional que recuerda el ideal socrático: "cuando Sócrates decía que una vida no sometida al libre albedrío -el famoso "conócete a ti mismo»- no es digna de ser vivida, no quería decir que ese examen fuera fácil; al contrario" (Charpak \& Omnès, 2005, p. 132). De hecho, difícilmente el común de los seres humanos se puede sustraer a "mecanismos poderosos que limitan la libertad humana y que incluso pueden llegar a aniquilarla" (Charpak \& Omnès, 2005, p. 133). Dentro de esto mecanismos se reconocen la alienación mental, la historia personal y las presiones sociales. De modo que un autoexamen cuidadoso debería encontrar maneras razonables de detectar estos mecanismos y someterlos a una reflexión crítica. 


\section{Bibliografía}

Arenas-Dolz, F. (2013). Los Trípodes de Hefesto. Valencia, España: Universidad de Valencia - Real Colegio de España.

Arendt, H. (1993). La condición humana. (G. Novales, Trad.) Barcelona, España: Paidós.

Arendt, H. (1996f). La crisis en la cultura: su significado político y social. En H. Arendt, Entre el pasado y el futuro. Ocho ejercicios sobre la reflexión política. (A. Poljak, Trad.). Barcelona, España: Península.

Arendt, H. (2005). La condición humana ( $3^{\mathrm{a}}$ ed.). Barcelona, España: Paidós.

Barceló, P., \& Hernández, D. (2014). Historia del pensamiento político griego. Teoría y Praxis. Madrid, España: Trotta.

Beuchot, M. (1998). La retórica como pragmática y hermenéutica. Barcelona, España: Anthropos.

Birulés, F. (1997). ¿Por qué debe haber alguien y no nadie? En H. Arendt, Qué es la política. Barcelona, España: Paidós/ICE/UAB.

Cadavid, L. (2013). Los sofistas: maestros del areté en la paideia griega. Perseitas, 2(1), 37-61. doi:http://dx.doi. org/10.21501/23461780.1128

Cassin, B. (2008). El efecto sofístico. Buenos Aires, Argentina: Fondo de Cultura Económica. 
Charpak, G. (2005). La main à la pâte. Science et Avenir, 1(698), 11.

Charpak, G., \& Omnes, R. (2005). Sed sabios, convertios en profetas. Barcelona, España: Anagrama.

Cicerón. (1995). De oratore I. Madrid, España: Gredos.

Damiani, A. (1993). Teoría y praxis en De Nostri. Temporis studiorum ratione. Cuadernos sobre Vico 3, 53-66.

Dilthey, W. (1977). Descriptive Psychology and Historical Understanding. The Hague: Nijhoff.

Dussel, E. (1975). El humanismo helénico. Buenos Aires, Argentina: Eudeba.

Espinosa, D. (2006). La educación griega y sus fuentes: aproximación a las épocas clásicas y helenísticas en Atenas. Espacio, tiempo $y$ formas. Serie II. Historia Antigua(1), 117-134. Recuperado el 25 de agosto de 2016, de http://studylib.es/doc/2524654/ la-educación-griega-y-sus-fuentes--helenísticas-en-atenas

Francisco. (3 de octubre de 2013). Discurso del Santo Padre Francisco a los participantes en un encuentro organizado por el Consejo Pontificio "Justicia y Paz" en el $50^{\circ}$ aniversario dela "pacem in terris". Recuperado el 29 de agosto de 2016, de Discursos: http:// w2.vatican.va/content/francesco/es/speeches/2013/october/ documents/papa-francesco_20131003_50-pacem-in-terris. html

Francisco. (25 de julio de 2013a). Visita a la comunidad de Varginha (Manguinhos). Discurso del Santo Padre Francisco. Recuperado el 25 de agosto de 2016, de Discursos: http://w2.vatican.va/content/francesco/es/speeches/2013/july/documents/ papa-francesco_20130725_gmg-comunita-varginha.html

Fromm, E. (1988). El arte de amar. Barcelona, España: Paidós. 
Gadamer, H. (1977). Verdad y método. Salamanca, España: Sígueme.

Gadamer, H. (1992). Verdad y método: fundamentos de una hermenéutica filosófica. Salamanca, Espańa: Sígueme.

Gadamer, H. (2000). Verdady Método II. Salamanca, España: Sígueme.

Gadamer, H. (2001). Antología. (C. Ruíz, \& M. Olasagasti, Trads.) Salamanca, España: Sígueme.

Gallagher, S. (2012). In defense of phenomenological approaches to social cognition: interacting with the critics. Rev Philos Psychol, 3(2), 187-212.

Goldmann, L. (1979). Epistemología de la sociología. En J. Piaget, Tratado de lógica y conocimiento científico (págs. 75 - 76). Buenos Aires, Argentina: Paidós.

Granjon, M. (1999). La prudence d'Aristote: histoire et pérégrinations d'un concept. Revue française de science politique, 49(1), 137-146. doi:10.3406/rfsp.1999.395359

Grondin, J. (2012). Fenomenología o hermenéutica: Un intento para comprender un afán común dentro de movimiento fenomenológico desde su práctica hermenéutica. En R. Rodríguez, Lenguaje y categorias en la hermenéutica fenomenológica (págs. 36-37). Madrid, España: Biblioteca Nueva.

Hardin, G. (1968). "The Tragedy of Commons" en Science. Gaceta Ecológica, 1(37), 1243-1248.

Hardin, G. (1995). La tragedia de los comunes. México, D. F.: Instituto Nacional de Ecología. Recuperado el 29 de agosto de 2016, de http://www.ine.gob.mx/

Jaeger, W. (1957). Paideia: los ideales de la cultura griega. (J. Xirau, Trad.) México, D. F.: Fondo de Cultura Económica. 
Jaeger, W. (1964). Humanismo y teología. (Estudio preliminar de A. Fontan). Madrid, España: Rialp.

Jonas, H. (1995). El principio de responsabilidad. Barcelona, España: Herder.

Lausberg, H. (1975). Elementos de retórica literaria. Madrid, España: Gredos.

Llamas, J. (2011). Bases de la educación occidental: la educación grecorromana, paleocristiana y medieval. En ,. O. Negrín, Historia de la educación española. Madrid, España: UNED.

Lobo, M. (2012). Hanna Arendt y la pregunta por la relación entre pensamiento y acción. Buenos Aires, Argentina: Biblos.

Mardones, J. (2007). Filosofía de las ciencias humanas y sociales: materiales para una fundamentación científica. Barcelona, España: Anthropos.

Marrou, H. (1998). Historia de la educación en la antiguedad (2a ed.). México, D. F.: Fondo de Cultura Económica.

Martínez Boom, A. (2004). De la escuela expansiva a la escuela competitiva: Dos modos de modernización educativa en América Latina. Barcelona, España: Anthropos.

Mazeaud, H. (2012). Métodos de trabajo. (O. Pérez, Trad.) Bogotá, D. C.: Universidad Externado de Colombia.

Milbank, J. (2004). Theology and social theory. Beyond secular reason. Oxford, G.B:: Blackwell.

Morando, D. (1968). Pedagogía: historia critica de las corrientes pedagógicas que han forjado el desarrollo de la educación. Barcelona, España: Luis Miracle. 
Nussbaum, C. (2005). El cultivo de la humanidad: una defensa clásica de la reforma en la educación liberal. Barcelona, España: Paidós.

Nussbaum, C. (2010). Sin fines de lucro: por qué la democracia necesita de las humanidades. Buenos Aires, Argentina: Katz.

Ordine, N. (2013). La utilidad de lo inútil (15a ed.). (J. Bayod, Trad.) Madrid, España: Acantilado Bolsillo.

Ortega y Gasset, J. (1983). Obras completas. Tomo VII. Madrid, España: Alianza.

Pannenberg, W. (1981). God's Presence in History. Christian Century, 98(3), 260-263.

Perelman, C., \& Olbrechts-Tyteca, L. (1989). Tratado de la argumentación. La Nueva Retórica. Madrid, España: Gredos.

Pérez, G. (2012). Retórica y paideia en el humanismo de la antigüedad tardia: las cartas de Libanio. (Tesis doctoral). Salamanca, España: Universidad de Salamanca. Facultad de Filología. Recuperado el 19 de agosto de 2016, de http://gredos.usal.es/jspui/bitstream/10366/121210/3/DFCI_PerezGaliciaGuillermo_Tesis. pdf

Peukert, H. (2000). Teoría de la ciencia y teología fundamental análisis del enfoque y de la naturaleza de la formación de la teoría teológica. Barcelona, Espańa: Herder.

Schaeffer, J. (1990). Sensus comunis: Vico, rethoric, and the limits of relativism. London, UK: Duke University Press.

Starck, C. (2010). Jurisdicción constitucional y derechos fundamentales. Madrid, España: Dykinson.

Tedesco, J. (2000). Educar en la sociedad del conocimiento. Buenos Aires, Argentina: Fondo de Cultura Económica. 



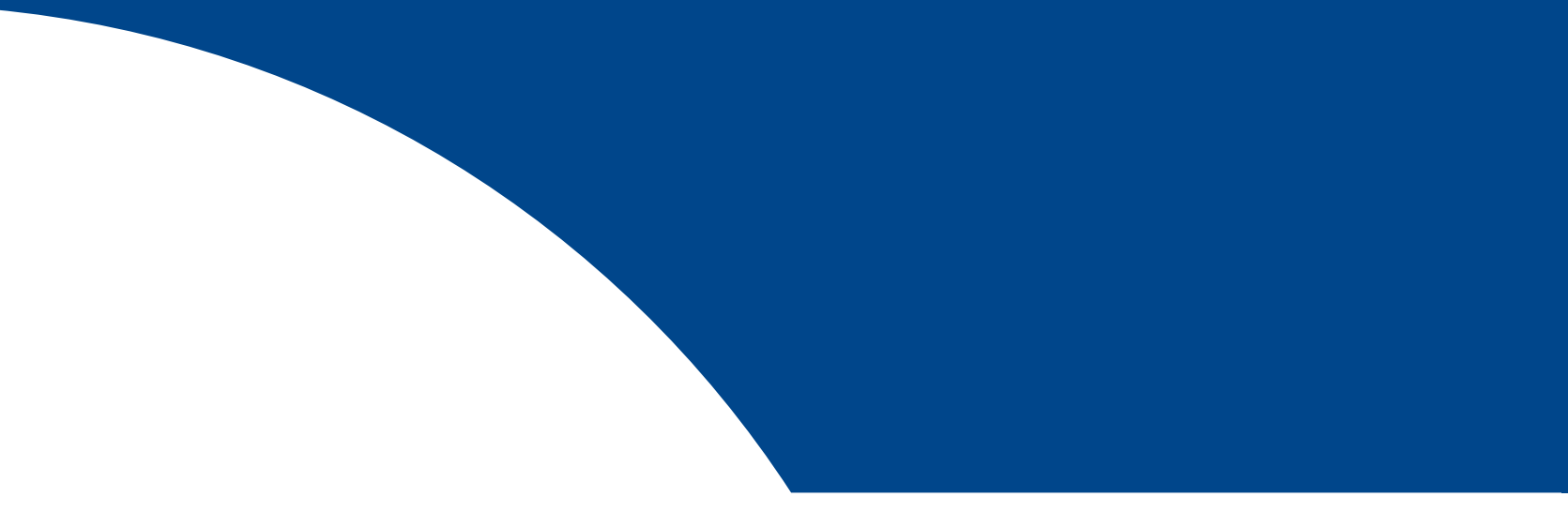

